\title{
BreastCore
}

\section{Psychosocial Care for Cancer Patients}

\author{
Joachim Weis \\ Abteilung Psychoonkologie, Klinik für Tumorbiologie, Freiburg i.Br., Germany
}

\section{Rationale of Psychosocial Care for Cancer Patients}

Due to advances in early detection and medical treatment of cancer in the past 3 decades as well as the increasingly higher life expectancy of the population, cancer incidence rates continue to rise worldwide [1]. As a consequence of these trends, an increasing number of people will require medical treatment for cancer, longterm surveillance, and palliative care in the future. Thus, cancer has turned into a life-threatening chronic condition for a large proportion of patients that poses new challenges for comprehensive cancer care. These include, among others, a change in the patient's role towards more active participation in treatment decisions and treatment itself depending on individual needs and expectations. Treatment may produce significant toxicities which cause substantial short- and long-term side effects, functional loss in various behavioral and life domains (physical, cognitive, emotional, social, and vocational), as well as psychosocial distress. Therefore, quality of life and functional status of the patients may be substantially reduced, and patients and their families are faced with many challenges in terms of coping and adjustment.

In the field of psycho-oncology, a subspecialty of oncology, various psychosocial strategies and interventions for prevention, early detection, assessment, and psychosocial care of cancer patients and their families have been developed [2]. There is high evidence that people with cancer suffer from psychosocial distress not only in the early stages following the diagnosis but during the entire course of the disease. Psychosocial distress includes many emotional, cognitive, social, and functional problems which have been documented in many studies. Concerns with their physical health, alterations to their normal development, emotional or mental health problems, and social problems (e.g., financial concerns/economic burden, reemployment/early retirement, stigma of disability, social and spiritual support concerns) have been identified [3]. Not only the patients but also their families are affected, often experiencing emotional distress, shifting of roles, financial burden, caregiver stress, and fear of losing their loved one [4].
Psychosocial distress is understood as a continuum ranging from normal distress levels such as fear, grief etc. up to high levels of distress and psychiatric comorbidity [5]. A recently published study on 4 weeks prevalence of psychiatric disorders in cancer patients in Germany showed an average prevalence rate of $36 \%$ of any psychiatric diagnosis across all diagnoses and treatment settings [6]. The 4-week total prevalence for any mental disorder was $31.8 \%$ (95\% confidence interval (CI) 29.8-33.8\%) with highest rates for anxiety disorder (11.5\%; 95\% CI 10.2-12.9\%), adjustment disorder (11.1\%; 95\% CI 9.7-12.4\%), or mood disorder (6.5\%; 95\% CI 5.5$7.5 \%)$. The highest prevalence for mental disorders was found in patients with breast cancer (41.6\%; 95\% CI 36.8-46.4\%).

Against this background and based on our knowledge about distress and psychiatric comorbidity in cancer patients, psychosocial care of cancer patients follows a structured stepped-care model starting with an early assessment and identification of a patient's psychosocial distress, psychiatric comorbidity, and individual needs $[2,7]$. Standardized and internationally validated instruments are available to assess psychosocial distress [8]. However, recently published results showed that early detection of distress and referral to psychosocial care does not automatically show a positive effect on a patient's quality of life and therefore should be embedded in a stepped-care program [9]. The stepped-care model comprises systematic identification of needs, integrated delivery of psychosocial care by care managers ranging from counseling to individual psychotherapy, and appropriate specialist supervision. The German Guideline for Psychooncology published in January 2014 is an evidence-based guideline for psychosocial assessment, counselling, and treatment of adult cancer patients. It follows the basic principles of care mentioned above [2]. Based on a systematic review for psycho-oncological interventions, relaxation techniques, psychoeducation, individual psychotherapy, group psychotherapy, as well as psychotherapeutic interventions with couples have been proven to be effective with a high level of evidence (LOE 1a) in terms of reducing anxiety and depression and improving quality of life [10].

\section{KARGER}

Fax +497614520714

\section{() 2015 S. Karger GmbH, Freiburg}

$1661-3791 / 15 / 0102-0084 \$ 39.50 / 0$
Prof. Dr. Joachim Weis 


\section{Barriers to the Delivery of Psychosocial Care}

Many studies focusing on the need assessment for patients with cancer have shown that at an average of $32 \%$ of cancer patients report the need for psychosocial care [2] covering a wide range of various psychosocial needs. Most commonly reported needs include help with coping with anxiety, depression, and fear of recurrence or progression, help with better communication, and support for relatives, families, or spouses [11-13]. Although psychosocial needs of cancer patients are well documented in the literature, there are existing barriers to the delivery of psychosocial care for cancer patients. Need assessment in psycho-oncology is estimated to be a complicated task due to the various influencing factors [14]. Patients often get support from their families or friends, have no clear information as to what to expect from psychosocial interventions, feel shame, and may also fear that disclosing their feelings may impair their emotional status $[15,16]$. A recently published review showed that the most commonly perceived barrier from the patients' perspective is related to receiving adequate support from elsewhere and a lack of perceived need for specific psychosocial care [17]. Another barrier is referring to clear and appropriate information about psychosocial services and knowledge about what types of psychosocial interventions could be helpful. For the patients, the role of psychosocial care in addition to existing medical support remains often unclear [18].

\section{Psychosocial Support for Cancer Patients in Healthcare}

Psychosocial care of cancer patients in acute hospitals is based on the model of psychosocial liaison or conciliar services delivered by the internal or external departments of psychosomatic medicine or psychiatry. Over the last 10 years in Germany, the German Cancer Society (DKG Deutsche Krebsgesellschaft e. V.) has established a certification system for cancer care centers to improve cancer care and ensure the highest standards of diagnosis and treatment in oncology [19]. Among the large number of various criteria for certification, professional psycho-oncological care is an essential part. Psychosocial care must be delivered to every patient who needs it. The certification system may be regarded as a milestone for improving the psychosocial care in cancer centers in Germany. However, the reality may be quite different as hospitals have often been reluctant to establish such services due to financial restrictions. Therefore, in a recently published study, the data from 456 certified cancer centers were analyzed addressing the quality of implementation of professional psychosocial care [20]. The data available show that psycho-oncological care has been improved in acute care, although there are still gaps in demand and delivery of services across urban and rural areas [21].

Rehabilitation should be started early in the process of cancer treatment to prevent or reduce long-term side effects. Cancer rehabilitation includes all coordinated efforts of multidisciplinary healthcare professionals to help patients overcome, minimize, or compensate the functional impairments and activity limitations brought about by the disease and its treatment $[22,23]$. Cancer rehabilitation requires an individual assessment of functional impairments to identify the relevant rehabilitation goals, and specify the interventions within the program. A variety of psychosocial interventions such as relaxation techniques, psychoeducation, individual psychotherapy, and counseling is delivered in inpatient or outpatient cancer rehabilitation. Results from evaluation research on the effectiveness of cancer rehabilitation at the level of either single interventions or rehabilitation programs as a whole show that such programs have short- and long-term effects on various outcome criteria [24, 25].

A working group within the German National Cancer Plan identified the largest deficits for the outpatient psychosocial care of cancer patient. Outpatient care is delivered by practicing psychotherapists, outpatient psychosocial services attached to clinic centers, or outpatient counseling services [2]. In Germany, outpatient psychosocial care is primarily based on psychosocial counseling services for cancer patients. It is estimated that overall more than 160 of such counselling services are established nationwide. In 2007, the German Cancer Aid ('Deutsche Krebshilfe e.V.') initiated and funded a program in 28 selected cancer counseling centers in Germany. First results of the evaluation of this program show that patients with breast cancer are the group with the highest percentage of using these services primarily within the first 2 years after diagnosis, with an average frequency of about 4 contacts per patient (own data).

\section{Conclusion}

Based on increasing knowledge about the influence of psychosocial factors on cancer and the significance of psychosocial support for cancer patients and their families, it has been demonstrated that overall psychosocial care in oncology has improved over the last 2 decades. The amount of scientific literature available in all sub-areas of psycho-oncology, focusing primarily on psychosocial distress, psychiatric comorbidity, psychosocial intervention, and quality of life research, reflects the increase in science-based knowledge in this field. Most studies in the field of psycho-oncology have focused on patients with breast cancer. Although evidence-based guidelines for psychosocial care have been published worldwide, gaps and barriers still exist in psychosocial care of cancer patients. It is encouraging that first studies on the effectiveness of an integrated treatment program (e.g. for major depression in patients with cancer) compared with usual care suggest that psychological care is an effective treatment for major depression in patients with cancer [18]. Early detection of psychosocial distress and identification of psychosocial care needs including the diagnosis of psychiatric comorbidity followed by a stepped-care model of interventions including counselling, psychoeducation, and psychotherapy seems to be the best approach to providing comprehensive psychosocial care for cancer patients. 


\section{Disclosure Statement}

The author declares that there are no conflicts of interest concerning the content of this editorial.

\section{References}

$D_{1}$ Ferlay J, Shin HR, Bray F, Forman D, Mathers C, Parkin DM: Estimates of worldwide burden of cancer in 2008: GLOBOCAN 2008. Int J Cancer 2010;127:28932917.

2 AWMF (2014) Leitlinienprogramm Onkologie (Deutsche Krebsgesellschaft, Deutsche Krebshilfe, AWMF): Psychoonkologische Diagnostik, Beratung und Behandlung von erwachsenen Krebspatienten. AWMFRegisternummer: 032/051OL, www.awmf.org/uploads/ tx_szleitlinien/032-051OLl_S3_Psychoonkologische_ Beratung_Behandlung_2014-01_1.1.pdf.

3 Brown ML, Lipscomb J, Snyder C: The burden of illness of cancer: economic cost and quality of life. Annu Rev Public Health 2001;22:91-113.

4 Longo CJ, Fitch M, Deber RB, Williams AP: Financial and family burden associated with cancer treatment in Ontario, Canada. Support Care Cancer 2006; 14:10771085.

5 Dalton SO, Laursen TM, Ross L, Mortensen PB, Johansen C: Risk for hospitalization with depression after a cancer diagnosis: a nationwide, populationbased study of cancer patients in Denmark from 1973 to 2003. J Clin Oncol 2009;27:1440-1445.

6 Mehnert A, Brähler E, Faller H, Härter M, Keller M, Schulz H, Wegscheider K, Weis J, Boehncke A, Hund B, Reuter K, Richard M, Sehner S, Sommerfeldt S,Szalai C, Hans-Ulrich Wittchen, Uwe Koch: Fourweek prevalence of mental disorders in patients with cancer across major tumor entities. J Clin Oncology 2014;32:3540-3546.

7 Andersen BL, DeRubeis RJ, Berman BS, Gruman J, Champion VL, Massie MJ, Holland JC, Partridge AH, Bak K, Somerfield MR, Rowland JH: Screening, assessment, and care of anxiety and depressive symptoms in adults with cancer: an American Society of Clinical Oncology guideline adaptation. J Clin Oncol 2014;32: 1605-1619.

8 Donovan KA, Grassi L, McGinty HL, Jacobsen PB: Validation of the distress thermometer worldwide: state of the science. Psychooncology 2014;23:241-250.
Braeken AP, Kempen GI, Eekers GP, Houben RM, van Gils FC, Ambergen T, Lechner L: Psychosocial screening effects on health-related outcomes in patients receiving radiotherapy. A cluster randomised controlled trial. Psychooncology 2013;22:2736-2746.

10 Faller H, Schuler M, Richard M, Heckl U, Weis J, Küffner R: Effects of psychooncological interventions on emotional distress and quality of life in adult cancer patients: systematic review and meta-analysis. J Clin Oncol 2013;31:782-793.

11 Sanson-Fisher R, Girgis A, Boyes A, Bonevski B, Burton L, Cook P: The unmet supportive care needs of patients with cancer. Supportive Care Review Group. Cancer 2000;88:226-237.

12 Schmid-Büchi S, Halfens RJG, Dassen T, van den Borne B: Psychosocial problems and needs of posttreatment patients with breast cancer and their relatives. Eur J Oncol Nurs 2011;15:260-266.

13 Sutherland G, Hill D, Morand M, Pruden M, McLachlan S-A: Assessing the unmet supportive care needs of newly diagnosed patients with cancer. Eur J Cancer Care (Engl) 2009;18:577-584.

14 Mehnert A: Zur Diskussion des Bedarfs psychosozialer Versorgung in der Onkologie. Discussing the Need for Psychosocial Care in Oncology. Psychother Psych Med 2014;64:251-252.

15 Coughlan R: Stigma, shame, and blame experienced by patients with lung cancer: health promotion and support groups have a role. BMJ 2004;329:402-403.

16 Eakin EG, Strycker LA: Awareness and barriers to use of cancer support and information resources by HMO patients with breast, prostate, or colon cancer: patient and provider perspectives. Psychooncology 2001;10: 103-113.

17 Dilworth S, Higgins I, Parker V, Kelly B, Turner J: Patient and health professional's perceived barriers to the delivery of psychosocial care to adults with cancer: a systematic review. Psychooncology 2014;23:601-612.
18 Sharpe M, Walker J, Hansen CH, Martin P, Symeonides S, Gourley C, Wall L, Weller D, Murray G; SMaRT (Symptom Management Research Trials) Oncology-2 Team: Integrated collaborative care for comorbid major depression in patients with cancer (SMaRT Oncology-2): a multicentre randomised controlled effectiveness trial. Lancet 2014;384:1099-1108.

19 Beckmann MW, Brucker C, Hanf V, Rauh C, Bani MR, Knob S, Petsch S, Schick S, Fasching PA, Hartmann A, Lux MP, Häberle L: Quality assured health care in certified breast centers and improvement of the prognosis of breast cancer patients. Onkologie 2011;34:362-367.

20 Singer S, Dieng S, Wesselmann S: Psycho-oncological care in certified cancer centres - a nationwide analysis in Germany. Psychooncology 2013;22:1435-1437.

21 Bergelt C, Schölermann C, Hahn I, Weis J, Koch U: Psychooncological care for breast cancer patients in hospitals and in the outpatient sector. Gesundheitswesen 2010;72:700-706.

22 Weis J, Giesler J: Rehabilitation for cancer patients; in. Goerling U (ed) Psycho-Oncology, Recent Results in Cancer Research, vol 107. Springer, Berlin, 2014, pp 87-101.

23 Hellbom M, Bergelt C, Bergenmar M, Gijsen B, Loge JH, Rautalahti M, Smaradottir A, Johansen C: Cancer rehabilitation: a Nordic and European perspective. Acta Oncol 2011;50:179-186.

24 Krüger A, Leibbrand B, Barth J, Berger D, Lehmann C, Koch U, Mehnert A: Verlauf der psychosozialen Belastung und gesundheitsbezogenen Lebensqualität bei Patienten verschiedener Altersgruppen in der onkologischen Rehabilitation. Z Psychosom Med Psychother 2009;55:141-161.

25 Haaf HG: Ergebnisse zur Wirksamkeit der Rehabilitation. Rehabilitation 2005;44:259-276. 